\title{
Combinations of Absorptive Capacity Metaroutines: The Role of Organizational Disruptions and Time Constraints
}

\begin{abstract}
This paper explores absorptive capacity metaroutines in a financial organization that experienced a large-scale misappropriation episode. We selected an instrumental case and collected individual semi-structured interviews, on-site nonparticipant observations, and documents to better understand the combination of absorptive capacity in organizational contexts. Findings revealed that the magnitude of organizational disruptions and time constraints influenced absorptive capacity metaroutines. The magnitude of organizational disruptions related to the intensity of required change for innovation adoption and the persistence of outcomes, while time constraints influenced the degree of involvement and cohesiveness of organizational members. In addition, findings showed that the combination of absorptive capacity metaroutines experienced asymmetries and had incremental and cumulative features. This work extends current theorizations of absorptive capacity conceptualized from a micro-foundation perspective as a collection of external and internal metaroutines and provides a means to start understanding potential factors that influence the combination of absorptive capacity metaroutines. Implications for theory and practice are discussed, and suggestions for future research are offered.
\end{abstract}

\section{Keywords}

Absorptive capacity, routines, metaroutines, micro-foundations, case study

\section{Introduction}

Absorptive capacity is "the ability to identify, assimilate, and exploit knowledge from the environment" (Cohen \& Levintal, 1989, p. 569-570) to meet organizational ends (Cohen \& Levinthal, 1990). Absorptive capacity has been investigated in several contexts including emerging markets (Bilgili, Kedia \& Bilgili, 2016), banking industries (Cepeda-Carrion, LealMillán, Martelo-Landroguez \& Leal-Rodriguez, 2016), and scientific settings (Belderbos, Gilsing \& Suzuki, 2015) and has been related to organizational processes (Sun, 2010; Knoppen, Sáenz \& Johnston, 2011), innovation outcomes (Helfat, 1997; Simonin, 1999; Hill \& Rothaermel 2003; Mariano \& Walter, 2015; Mariano \& Casey, 2015; Gebauer, Worch \& Truffer, 2012; Tsai \& Yang, 2015; Lichtenthaler \& Lichtenthaler, 2009), innovative performance (Tseng, Pai \& Hung, 2011; Ali, Kan \& Sarstedt, 2016; Denicolai, Ramirez \& 
Postprint version of:

Mariano, S., \& Al-Arrayed, S. (2018). Combinations of absorptive capacity metaroutines: the role of organizational disruptions and time constraints. European Management Journal, 36(2), 171-182. https://doi.org/10.1016/i.emi.2017.03.003

Tidd, 2016; Kim, Kim \& Foss, 2016), and organizational performance (Lichtenthaler, 2016; Brettel, Greve \& Flatten, 2011; Ben-Oz \& Greve, 2012). Existing conceptualizations of absorptive capacity have pointed out its inter- and intra-organizational antecedents (Volberda, Foss \& Lyles, 2010; Martinkenaite \& Breunig, 2016); discussed its mediating (Cockburn \& Henderson, 1998) or moderating role in organizational innovative capabilities (Koza \& Lewin, 1998; Tsai \& Yang, 2015); distinguished between potential and realized absorptive capacity (Zahra \& George, 2002; Andersén \& Kask, 2012; Ben-Oz \& Greve, 2012; Kang \& Lee, 2016), with recent empirical work confirming a linear relationship among the internal components of absorptive capacity (Daspit \& D'Souza, 2013); attempted to operationalize the construct (Flatten, Engelen, Zahra \& Brettel, 2011; van der Heiden, Pohl, Mansor \& van Genderen, 2016); and theorized about the existence of complementarities between its internal components (Todorova \& Durisin, 2007). Because the construct has significantly expanded over the years, several reviews have also been conducted to synthesize existing theoretical discussions and empirical contributions, focusing on a managerial (Lane, Koka \& Pathak, 2006), information systems (Roberts, Galluch, Dinger \& Grover, 2012), or knowledge management and intellectual capital perspective (Mariano \& Walter, 2015; Senivongse, Mariano \& Bennet, 2015).

Although the debate has exponentially grown over the years, with research introducing refinements and, at times, substantial changes to the construct (Zahra \& George, 2002; Todorova \& Durisin, 2007), scholars have not yet reached a common understanding of what still appears to be a controversial phenomenon of investigation. Current research has agreed upon and theorized that acquisition, assimilation, transformation, and exploitation are the four major components of absorptive capacity, proposing their sequential (Zahra \& George, 2002) or complementary (Todorova \& Durisin, 2007) relationship conditioned by antecedents and contingency factors whose influence has been differently theorized in the literature (Volberda et al., 2010; Lewin, Massini \& Peeters, 2011).

However, research has still not yet understood the extent to which absorptive capacity capabilities relate to each other (Jansen, Van Den Bosch \& Volberda, 2005) and how internal capabilities and routines are likely to increase new knowledge absorption (Lane et al., 2006; Lewin \& Massini, 2003; Lewin et al., 2011; Inkpen, 1998), largely because of the proven struggle in the operationalization of the construct, which has forced the use of indirect methods of evaluation and proxy measures such as patents (Mowery \& Oxley, 1995), self- 
Postprint version of:

Mariano, S., \& Al-Arrayed, S. (2018). Combinations of absorptive capacity metaroutines: the role of organizational disruptions and time constraints. European Management Journal, 36(2), 171-182. https://doi.org/10.1016/i.emi.2017.03.003

reports (Szulanski, 1996), relative absorptive capacity measures (Lane \& Lubatkin, 1998), and R\&D spending (Veugelers, 1997).

To overcome the limits of current theorizations whose empirical observation remains a challenging attempt, more recent contributions have proposed the study of absorptive capacity from a micro-foundation perspective that investigates observable organizationspecific routines and metaroutines (Lewin \& Massini, 2003; Lewin et al., 2011), in the hope of clarifying and helping in identifying those external and internal mechanisms that contribute to knowledge absorption but still remain largely ambiguous and unclear (Lewin \& Massini, 2003; van der Heiden et al., 2016). Compared to previous theorizations emphasizing the sequential nature of absorptive capacity potential and realized capabilities (Zahra \& George, 2002), its strengthening influence on learning processes (Lane et al., 2006; FerrerasMéndez, Fernández-Mesa \& Alegre 2016), or the alternative path of its assimilation and transformation components (Todorova \& Durisin, 2007), the micro-foundation perspective distinguishes between internal and external absorptive capacity capabilities and relate them to higher level absorptive capacity metaroutines (Lewin et al., 2011). Metaroutines are in turn connected to organization-specific routines that are observable in nature and whose combination is proposed to influence an organization's overall absorption levels. From a micro-foundation perspective, this would thus explain the reasons why some organizations are better at externally acquiring relevant new knowledge and internally absorbing it, while others struggle in achieving similar results because of differences in the combination of their external and internal metaroutines and organization-specific routines.

Therefore, the study of absorptive capacity from a metaroutines perspective aims to guide explorations of microdynamics that are likely to promote higher levels of knowledge absorption. From a theoretical perspective, discovering and documenting the combination of metaroutines and organization-specific practiced routines will contribute to a refined understanding of absorptive capacity internal and external influencing factors, the complementarities and combinative capabilities of its components, and the interactions that occur at the interface between the two levels. From a practitioner perspective, the study of absorptive capacity metaroutines will help managers select and combine those practices that will more likely produce higher levels of knowledge absorption, which, in turn, will have a positive influence on exploitative and innovative capabilities at the organizational level. 
Postprint version of:

Mariano, S., \& Al-Arrayed, S. (2018). Combinations of absorptive capacity metaroutines: the role of organizational disruptions and time constraints. European Management Journal, 36(2), 171-182. https://doi.org/10.1016/i.emi.2017.03.003

This study aims, thus, to contribute to the absorptive capacity debate from a microfoundation perspective to help explain factors that are more likely to influence internal and external absorptive capacity metaroutines in a financial organization that experienced a largescale misappropriation episode. To accomplish this aim, we selected an instrumental case and collected individual semi-structured interviews, observations, and documents.

Findings revealed that the magnitude of organizational disruptions and time constraints influenced absorptive capacity metaroutines and that intensity of required change for innovation adoption, persistence of outcomes, and degree of involvement and cohesiveness of organizational members connected to these factors. In addition, findings showed that the combination of absorptive capacity metaroutines experienced a certain level of asymmetries and had incremental and cumulative features.

In this study, we define metaroutines as "higher-level routines that define the general, abstract purpose of routines that are expressed by practiced routines, which are firm specific, idiosyncratic, and observable" (Lewin et al., 2011, p. 85); we define organizational knowledge as valuable information that becomes embedded in new routines and practices. This definition derives from the academic debate on dynamic capabilities (Teece, Pisano \& Shuen, 1997; Zollo \& Winter, 2002; Helfat, 1997; Helfat et al., 2009) that measures organizational knowledge as a change in internal routines or practices so that learning has occurred (Levitt \& March, 1988).

This paper is organized as follows. First, we briefly discuss the theoretical background. We then move to the case study methodology (Stake, 1995) including the discussion of research setting and design, data collection and analysis procedures, quality assurance techniques, and ethical considerations. We report findings in a narrative way (Creswell, 2009), and we support these findings with the use of tables and verbatim illustrative quotations from interview transcripts. Finally, we discuss conclusions, implications for theory and practice, limitations, and future research directions.

\section{Theoretical background}

\subsection{Absorptive capacity major developments}

The construct of absorptive capacity was first introduced by Cohen and Levinthal (1990) to explain the capacity of an organization to recognize, acquire, and exploit external knowledge with the intent to innovate, adapt, and being flexible. In their seminal work, 
Postprint version of:

Mariano, S., \& Al-Arrayed, S. (2018). Combinations of absorptive capacity metaroutines: the role of organizational disruptions and time constraints. European Management Journal, 36(2), 171-182. https://doi.org/10.1016/i.emi.2017.03.003

Cohen and Levinthal conceptualized absorptive capacity as a dual construct of external and internal capabilities enabling knowledge absorption processes. Knowledge source and prior knowledge were conceptualized as antecedents of absorptive capacity, while ex-ante appropriability regimes (e.g., spillovers) were proposed to influence performance. Over the years, the construct received increased interests and grew exponentially, with many attempts of operationalization (Flatten et al., 2011; van der Heiden, Pohl, Mansor \& van Genderen, 2016) and refinements (Zahra \& George, 2002; Lane et al., 2006; Todorova \& Durisin, 2007; Volberda et al., 2010; Andersén \& Kask, 2012).

In the work of Zahra and George (2002), absorptive capacity was re-conceptualized from the seminal work (Cohen \& Levinthal, 1990) into two distinct but related capabilities, i.e., potential and realized absorptive capacity, where the former related to the acquisition and assimilation components, while the latter referred to transformation and exploitation components. In this refined model, absorptive capacity was linked to competitive advantage expressed in terms of flexibility, innovation, and performance. Knowledge source, complementarities, and prior knowledge were conceptualized as potential antecedents of the construct, while activation triggers, social integration mechanisms, and regimes of appropriability were theorized as contingency factors. Compared to Cohen and Levinthal's (1990) seminal work, Zahra and George (2002) introduced new elements such as complementarities, activation triggers, and social integration mechanisms and theorized the existence of ex-post appropriability regimes. Most importantly, Zahra and George (2002) introduced and distinguished between potential and realized absorptive capacity and conceptualized them as two distinctive but sequential capabilities conceived as a better representation of the uncertainty derived from capturing and exploiting external new knowledge.

Contrary to Zahra and George's (2002) theorization of absorptive capacity, the conceptualization by Lane et al. (2006) derived its arguments from an extensive and critical literature review of 289 key papers in 14 top-tier journals bringing into discussion exploratory, transformative, and exploitative learning capabilities connected to absorptive capacity components such as recognition, assimilation, and application. Environmental conditions together with characteristics of firm structures and workforce and firm strategies and outcomes were also included into Lane et al.'s (2006) process model of absorptive capacity, which contributed to the debate relating absorptive capacity to organizational learning in a strengthening and reciprocal relationship (Barkema \& Vermeulen 1998; 
Postprint version of:

Mariano, S., \& Al-Arrayed, S. (2018). Combinations of absorptive capacity metaroutines: the role of organizational disruptions and time constraints. European Management Journal, 36(2), 171-182. https://doi.org/10.1016/i.emi.2017.03.003

Simonin, 1999; Autio, Sapienza \& Almeida, 2000; Zollo \& Winter, 2002) mediated by environmental influences (Van den Bosch, Volberda \& de Boer, 1999).

Todorova and Durisin (2007) refined the re-conceptualization of Zahra and George's (2002) model and introduced significant changes. They proposed the same outcome theorized in Zahra and George's (2002) refined model but discarded complementarities as a potential antecedent, and reintroduced the recognition of the value of new knowledge as originally proposed in Cohen and Levinthal's (1990) work. Their refined conceptualization did not consider the distinction between potential and realized absorptive capacity capabilities and rearranged the four components of acquisition, assimilation, transformation, and exploitation in new ways. According to this new conceptualization, acquisition was proposed to precede both assimilation and transformation components, while assimilation and transformation were theorized as alternative components preceding knowledge exploitation. Contingency factors such as appropriability regimes were conceptualized at the beginning and at the end of the absorptive capacity process, and the new concept of power relationships was introduced and added to activation triggers and social integration mechanisms.

Over the years, these proposed conceptualizations will become widely discussed in the literature, although research has not yet found a common agreement on which conceptualization would best explain absorptive capacity dynamics in organizations. This is perhaps because the other variables were also brought into the discussion, such as the mediating role of the environment in the feedback loop between absorptive capacity and learning processes (Van den Bosch et al., 1999); the role of dynamic capabilities in absorptive capacity processes that has evolved from initial conceptualizations of internal and external competences to deal with a rapidly changing and turbulent environment (Teece et al., 1997) to more recent conceptualizations that have considered the role and importance of resource reconfigurations (Eisenhardt \& Martin, 2000), learning processes (Zollo \& Winter, 2002), or knowledge-based dynamics (Denford, 2013; Zahra \& George, 2002); and the conspicuous numbers of managerial (Sciascia, D’Oria, Bruni \& Larrañeta, 2014), interorganizational (Hurmelinna-Laukkanen, Olander, Blomqvist \& Panfilii, 2012; Martinkenaite \& Breunig, 2016) and intraorganizational antecedents of absorptive capacity (Volberda et al., 2010), which made the theorization of the construct even harder to be explained.

\subsection{Understanding absorptive capacity as a collection of metaroutines}


Postprint version of:

Mariano, S., \& Al-Arrayed, S. (2018). Combinations of absorptive capacity metaroutines: the role of organizational disruptions and time constraints. European Management Journal, 36(2), 171-182. https://doi.org/10.1016/i.emi.2017.03.003

Recent theorizations (Lewin et al., 2011) and empirical contributions (Peeters, Massini \& Lewin, 2014) suggested an alternative way to investigate absorptive capacity from a micro-foundation perspective that brings back the initial dual conceptualization of Cohen and Levintal's (1990) work and distinguishes between external and internal capabilities conceptualized as groups of metaroutines and organization-specific routines that enable knowledge absorption processes.

Lewin et al. (2011) derived this alternative perspective from a review of the absorptive capacity literature, which highlighted the use of proxy measures (such as patents or R\&D indicators) in academic investigations, and pointed out the lack of direct measurements of the construct. To overcome such a shortfall, they proposed a model of internal and external absorptive capacity routines interconnected through adaptive tension mechanisms (from internal to external metaroutines) and transfer mechanisms (from external to internal metaroutines). Internal absorptive capacity metaroutines included facilitation of variation; internal selection regimes; knowledge sharing and superior practices across the organization; and reflection, updating, and replication metaroutines. External absorptive capacity metaroutines included identification and recognition of valuable knowledge, and learning from and with external collaborators such as partners, suppliers, customers, competitors, and consultants. Sociocultural values, norms, and mechanisms were proposed as moderators, and each metaroutine was linked to a group of organization-specific routines, which were idiosyncratic and context-specific and proposed to be best investigated through empirical and direct observations.

To study absorptive capacity from a metaroutines perspective, empirical research thus needs to map internal and external mechanisms and dynamics occurring at the intersection between the two levels. Of particular interest are those investigations of organization-specific routines, which are observable in nature, and whose mechanisms are still not clear, although hold concrete potentials to explain those components and combinative capabilities that may directly influence absorptive capacity at the organizational level. This is the purpose of the present study aiming at exploring the combination of metaroutines and organization-specific routines as described by the members of a financial organization. Our overall aim is to increase the current understanding of those factors influencing absorptive capacity from a micro-foundation perspective, an alternative view of absorptive capacity also supported by works on organizational routines, which suggests a link between internal meta-processes of variation, selection and replication and existing organizational routines (Zollo \& Winter 
Postprint version of:

Mariano, S., \& Al-Arrayed, S. (2018). Combinations of absorptive capacity metaroutines: the role of organizational disruptions and time constraints. European Management Journal, 36(2), 171-182. https://doi.org/10.1016/i.emj.2017.03.003

2002; Postrel \& Rumelt, 1992; Cohen, 1991; Louis \& Sutton, 1991; Gersick \& Hackman, 1990; Weiss \& Ilgen, 1985; Mariano \& Casey, 2016).

\section{Methodology}

\subsection{Research setting}

The research setting of this study is Alphasource (pseudonym), a financial organization that provides credit card-related solutions and services. The organization had a functional structure with 6 departments and employed 120 individuals at the time of data collection.

In 2011, Alphasource experienced a large-scale external and internal misappropriation episode, which forced the organization to find and adopt more innovative security solutions for existing and new products and to provide improved customer care services and support. Alphasource had to remodel its internal routines to make room for these new innovative solutions which, because of the misappropriation episode, had to be adopted in a short period of time. These actions required the maximization of internal and external absorptive capacity capabilities and the development (or, at time, replacement) of routines due to the experienced period of crisis (Nelson \& Winter, 1982). The distinctiveness of this research setting helped our understanding of absorptive capacity metaroutines and their combinative features (Lewin et al., 2011) and provided a means to better understand the emergence of certain metaroutines that appeared to be superior to others. For these reasons, Alphasource provided the best research setting to conduct our study because of the likely manifestation of the phenomenon of interest (Eisenhardt, 1989) and the potential maximization of the researchers' learning experiences.

\subsection{Research design}

We adopted a relativist ontological perspective where phenomena depend on the perspectives from which they are observed (Easterby-Smith, Thorpe \& Jackson, 2012; see also Latour \& Woolgar, 1979), taking a social constructionist epistemological position where reality is determined by individuals (Easterby-Smith et al., 2012; Berger \& Luckman, 1966; Shotter, 1993; Habermas, 1970). From a methodological perspective, we employed an instrumental case study for process tracing because of a predetermination of the research questions and conceptual framework and a need for an in-depth understanding of the phenomena studied (Stake, 1995, p. 3). The level of analysis was the organization, and our 
Postprint version of:

Mariano, S., \& Al-Arrayed, S. (2018). Combinations of absorptive capacity metaroutines: the role of organizational disruptions and time constraints. European Management Journal, 36(2), 171-182. https://doi.org/10.1016/i.emi.2017.03.003

interest was on the factors influencing the combination of absorptive capacity metaroutines and organization-specific routines in a financial organization (Volberda et al., 2010).

\subsubsection{Data collection methods and ethical considerations}

The Head of Client Services (fictional name) assisted the access to the research setting and provided ongoing support throughout the entire research journey clarifying, with formal and more informal interviews and countless conversations, our reflective and interpretive processes, contributing to the validation of our research findings (Marshall, 1996; Seale, 1999). Overall, we found a very collaborative research setting where both managers and employees happily shared their experiences and insights and helped us enormously in our sense-making process (Eisenhardt \& Graebner, 2007). Because of the holistic nature of our research questions and design, we purposefully selected (Miles \& Huberman, 1994) and interviewed participants across all departments. Participation was voluntary, anonymous, with the possibility to withdraw at any time (Patton, 2002).

Data were primarily collected through 26 individual semi-structured interviews (Merriam, 2001; Creswell, 2009) conducted across 8 departments between January and April 2013. They helped guide conversations rather than structured queries (Rubin \& Rubin, 1995) and contributed to the surface of findings. Participants (29\% female) were selected according to a purposeful sampling technique, i.e., snowball sampling (Lincoln \& Guba, 1985) and included the managerial level (33\%) to increase the quality of collected data and guarantee maximum variation (Lincoln \& Guba, 1985). Interviews lasted an hour on average and were all digitally recorded and transcribed verbatim within 48 hours. Interview questions employed the critical incident technique (Flanagan, 1954) and related to absorptive capacity components and mechanisms. Interview questions related, for instance, to recent changes that affected organizational routines and knowledge absorption processes, the outcomes of these changes, and their impact on processes and procedures. Interviews concluded with a general question asking participants for additional comments that could help and be relevant to the research study. These questions were refined after two pilot interviews. Several probe questions were also added during the process to benefit from emerging patterns and themes. For example, asking to provide more details on specific routines that emerged during the conversation or seeking for additional examples to better understand the internal knowledge adjustment phases, which emerged as one of our key findings. In five cases, we conducted 
Postprint version of:

Mariano, S., \& Al-Arrayed, S. (2018). Combinations of absorptive capacity metaroutines: the role of organizational disruptions and time constraints. European Management Journal, 36(2), 171-182. https://doi.org/10.1016/i.emi.2017.03.003

follow-up interviews to gain additional knowledge and clarify emerging themes. These follow-up interviews lasted an average of 45 minutes (see Table 1).

Although our findings rely mainly on primary data (i.e., semi-structured interviews), we also acknowledge the collection of secondary data, specifically in-site nonparticipant observations, and private and public documents. In-site nonparticipant observations (Miles \& Huberman, 1994; Creswell, 2009) were conducted during several visits to the research setting and enabled the observation of day-to-day activities in different departments. The second author observed the climate of the organization and the formal and informal interactions. This opportunity added great value and increased our understanding of the research context. In total, 15 observational hours were spent in the research setting. Documents (Miles \& Huberman, 1994) were also collected and helped data triangulation (Jick, 1979). These documents included internal policies and reports, guidebooks, meeting agendas between departments, and online electronic repositories.

Upon company's request, real names of participants, job titles, and departments were masked, and participants' identities were labeled using progressive numbers, i.e., P1. The location at which the organization operates was also undisclosed for the same reasons and because of the sensitivity of the explored topics and the type of collected data.

\section{Insert Table 1 here}

\subsubsection{Data analysis methods}

Data collection and analysis processes were iterative. After each wave of data collection, which corresponded to an average of five individual semi-structured interviews, we modified the interview protocol and added new questions to benefit from emerging themes (Lincoln \& Guba, 1985).

A preliminary list of codes was prepared based on research questions, conceptual models, assumptions, and literature review (Miles \& Huberman, 1994). Preliminary codes were, for example, relevance of knowledge, knowledge assimilation, knowledge transformation, and knowledge exploitation. Additional in vivo codes, e.g., cohesiveness, were added during the analysis of transcripts to capture the words that participants most used 
Postprint version of:

Mariano, S., \& Al-Arrayed, S. (2018). Combinations of absorptive capacity metaroutines: the role of organizational disruptions and time constraints. European Management Journal, 36(2), 171-182. https://doi.org/10.1016/i.emj.2017.03.003

in their rich and personal descriptions. Interview transcripts were initially open-coded and substantially re-coded after new codes emerged. Usually codes were attributed to single sentences or longer paragraphs. Some codes were abandoned, and others were added or grouped during the entire analysis process until a final version was reached, for example merging the codes "cycles of changes" with "cumulativeness" because they both described enhancements in the adjustment process described by our participants. When patterns and themes began to emerge, we grouped them and prepared summaries and tables (Tables 2 and 3 and Appendix A).

To increase the quality of the analysis, inter-code reliability was applied. We coded the interview transcripts separately, and we also asked an independent researcher, who in our case was a graduate student who had expertise in qualitative methods, to randomly code selected interview transcripts. Dissimilarities were discussed until a final agreement was reached. During the entire process of data collection and analysis, we kept an electronic journal with our own thoughts, emerging ideas, and preliminary potential explanations to enable systematic reflections and complex reasoning that could be multifaceted, iterative, and simultaneous (Rossman \& Rallis, 1998; Cresswell, 2009). For validation purposes (Marshall, 1996; Seale, 1999), we discussed our findings with the Head of Client Services who served as the key informant of this research project.

\section{Findings: Mapping internal and external absorptive capacity metaroutines}

When we entered the research setting, our aim was to better understand absorptive capacity metaroutines at Alphasource, being aware of the recent challenges faced by the organization, because of the conspicuous amount of new knowledge that was introduced and had to be absorbed.

We discovered that the large-scale external and internal misappropriation episode represented a trigger point in the absorptive capacity process because the organization was forced to find and adopt innovative and more sophisticated security solutions for its products and services to maintain customers and reputation and, ultimately, to survive. These solutions had to be quickly absorbed and implemented; therefore, they required high involvement levels among organizational members and overtime working hours (with corresponding increased duties) for key employees. When we realized that the trigger point was very well described by its magnitude - in terms of intensity of required changes for innovation adoption and persistence of outcomes - and the time constraints factor, we started mapping the 
Postprint version of:

Mariano, S., \& Al-Arrayed, S. (2018). Combinations of absorptive capacity metaroutines: the role of organizational disruptions and time constraints. European Management Journal, 36(2), 171-182. https://doi.org/10.1016/i.emi.2017.03.003

absorptive capacity internal and external metaroutines and organization-specific routines involved (Lewin et al., 2011) and the way absorptive capacity was pursued and achieved.

We provide a detailed description of these findings in the following sections with regard to the chain of events that occurred at Alphasource during a year period, the influence of organizational disruptions and time constraints, and the resulting combination of absorptive capacity metaroutines, which presented internal asymmetries and appeared to be cumulative in nature.

\subsection{Chain of events at Alphasource}

The discovery of the large-scale external and internal misappropriation episode represented the trigger point in the chain of events at Alphasource. This specific episode required urgent and immediate attention and translated into multiple and overlapping actions targeting individuals, products, and processes that had to be corrected, replaced, or integrated with new and improved organization-specific routines (see also Table 2), as described below:

Individuals: These actions regarded the performance of internal investigations and audit sessions, recruitment and discharge of organizational members, arrangement of training sessions, and implementation of job rotation mechanisms.

Products: These actions related to the core of the innovation process and regarded the replacement or use of new credit cards and related products with more secure and sophisticated mechanisms to perform online and offline transactions.

Processes: These actions regarded the entire set of supporting processes, including, among others, notification and assistance services, monitoring systems, and prototyping. Later on, we found out that many of these routines were highly interdependent and complementary.

Insert Table 2 here

After we recreated the list of actions taken by Alphasource to face the large-scale external and internal misappropriation episode, we moved to a more detailed analysis of absorptive capacity metaroutines. With the exception of one internal and one external 
Postprint version of:

Mariano, S., \& Al-Arrayed, S. (2018). Combinations of absorptive capacity metaroutines: the role of organizational disruptions and time constraints. European Management Journal, 36(2), 171-182. https://doi.org/10.1016/i.emi.2017.03.003

metaroutine (i.e., "facilitating variation" and "identifying and recognizing value of externally generated knowledge"), we could reconstruct almost the entire set of metaroutines as theorized by Lewin et al. (2011) and extend this theorization with additional insights related to organization-specific routines and to potential determinants of metaroutines combination.

We found out that the unique circumstances faced by Alphasource defined a highly contextspecific configuration of absorptive capacity metaroutines. Externally, this configuration included learning processes from consultants and suppliers and, to a lesser extent, from customers, while internally they failed to include the facilitation of variation regimes. We, however, encountered many examples of "sharing knowledge and superior practices," and "reflection, updating, and replication" mechanisms, which seemed to be the two largest groups of observed internal metaroutines. A summary supported by empirical evidence is provided in Table 3.

Insert Table 3 here

\subsection{Magnitude of organizational disruptions and time constraints}

From the analysis of data, two major factors - conditioned by the misappropriation episode - appeared to influence internal and external metaroutines: magnitude of organizational disruptions and time constraints. The former appeared to be explained by the intensity of required change for innovation adoption and the persistence of outcomes; the latter seemed to relate to the degree of involvement and cohesiveness of organizational members.

Intensity and persistence. Intensity of required change for innovation adoption seemed to describe the amount of interdependencies and replacements required to ensure appropriate organizational change. At Alphasource, these replacements manifested uniformly and created interdependencies across all departments, although it appeared that the biggest example involved the Technological Development Department whose members had to carry out multiple actions to substitute the technological infrastructures at all levels and deal with unexpected issues that, if not fixed, could compromise other departments and, ultimately, the survival of the entire organization: 
Mariano, S., \& Al-Arrayed, S. (2018). Combinations of absorptive capacity metaroutines: the role of organizational disruptions and time constraints. European Management Journal, 36(2), 171-182. https://doi.org/10.1016/i.emi.2017.03.003

“...at some points you would think to yourself that to fix the whole IT system of an organization in such a short period of time is almost impossible. There were some times that we would feel very frustrated, especially when the system was unresponsive to us. You know how technology can be sometimes, so to me, what we had done was of great hard work and determination" (P5, Manager).

From the data analysis, it was clear that the intensity of required change for innovation adoption had to produce long-lasting outcomes to ensure organizational survival. Participants referred to this emerged theme-labeled "persistence of outcomes"-in terms of "maintaining the name of the organization," "keep VIP and loyal customers," and "maintain its [the organizational] reputation in the market." Several internal absorptive capacity metaroutines of "reflection, updating, and replication" processes (Lewin et al., 2011) also supported this finding and regarded, among others, the arrangement of audit sessions (and follow-ups), the introduction of a stable monitoring system, and the replacements of old credit cards and related services and solutions in the hope of creating long-lasting benefits that would overcome the negative effects generated by the misappropriation episode:

"I would say the reason for these many changes is to have extra security and for this [the misappropriation episode] not to occur again” (P1, Manager).

"The main aim was to have the company running the way it used to be, maintaining its reputation in the market" (P17, Employee).

"These [all the changes related to credit cards] were made to provide extra security to the cards and to the system itself in order for situations as big as a fraud not to occur again” (P11, Employee).

Degree of involvement and cohesiveness. Time constraints emerged as crucial boundary conditions of Alphasource's operations and appeared to influence how organizational members collaborated with each other's. Early in our data analysis, it became clear that two key factors (labeled "degree of involvement" and "cohesiveness") related to time constraints and described the individual involvement and group cohesiveness in the implementation of new metaroutines, respectively. Our participants recalled many instances where employees had to work overtime to reduce mistakes and guarantee daily external and internal assistance to current customers and to other departments. This was especially evident 
Postprint version of:

Mariano, S., \& Al-Arrayed, S. (2018). Combinations of absorptive capacity metaroutines: the role of organizational disruptions and time constraints. European Management Journal, 36(2), 171-182. https://doi.org/10.1016/i.emi.2017.03.003

with the Technological Development Department whose strenuous assistance showed to be crucial during internal absorption processes. Consider the following supporting exemplars:

“Technological Development Department did a great job of making sure all was adjusted. They would work sometimes over time in order for the system to be up and running for us when we came in the morning and would monitor the system in order for the work to process very smoothly" (P1, Manager, Follow-up).

“They [Technological Development Department] definitely did an outstanding job as we would come in every morning and updated software would have been installed for us and the manager dedicated an IT employee for each department in order to assist with any difficulties with the new system and adjust it to run smoothly" (P2, Manager, Follow-up).

“We had some members who worked for over 24 hours" (P4, Manager, Follow-up).

Cohesiveness among organizational members - including employees, and top and middle managers - seemed also to relate to time constraints and describe the joined effort exercised to perform new routines within certain time-varying boundary conditions. This joined effort involved multiple individuals across numerous departments and defined an organizational environment where coordination and absorption processes occurred as a result of the micro- and mesolevels and whose outcomes had a direct impact on the macrolevel (i.e., organizational level). Consider the following statements:

"Our team, which we consider ourselves to be as one big family, was determined to have our organization the same as it was before; therefore employees, even those who had families, worked overtime” (P2, Manager).

"All the employees from our department worked united as one team in order to have our system back and running again. They all worked together overtime just to get back to normal" (P3, Manager).

"I think the learning, adapting, and implementing processes went smooth. I think that it was due to the hard work and dedication of the company's team and also the hard efforts and long working hours faced by the top management" (P11, Employee). 
Postprint version of:

Mariano, S., \& Al-Arrayed, S. (2018). Combinations of absorptive capacity metaroutines: the role of organizational disruptions and time constraints. European Management Journal, 36(2), 171-182. https://doi.org/10.1016/i.emj.2017.03.003

Another example regarded the provisional interruptions experienced by both the call center and the internal information technology system. In this case, other departments arranged supporting actions to replace or complement missing routines:

“...there were a lot of information technology difficulties and disputes to handle with the system, so we had to have the system switched off and we had to deal with a lot of our transitions manually" (P9, Employee).

"Our call center had to stop operating for a while, and staff from our department had to take their place. During that time the call center team was trained and updated with the new procedures of our system" (P1, Manager, Follow-up).

A final example referred to the management of adaptive tension (Lewin et al., 2011) across several departments including marketing, customer services, and dispute that had to elaborate jointly internal information to provide reassuring advises to customers and minimize disruptions:

"When we finally had some bit of information about the issuing of new cards, it was easy for us to come-up with a marketing campaign...once we had a clear idea of what the functions and factors of the new introduced cards were, our marketing and selling campaign was easy” (P6, Manager).

"We had the client service department helping us informing our clients, but I had to deal with the angry and difficult customers, which made the job harder" (P18, Supervisor).

\subsection{Combinations of metaroutines}

Our data also seemed to suggest two additional findings: (1) Absorptive capacity metaroutines were context-specific and their implementation appeared to be asymmetrical across the entire organization. Consequently, certain departments or group of individuals experienced higher or lower absorptive capacity levels than others; (2) absorptive capacity appeared to be cumulative and, as a whole, the combination of absorptive capacity metaroutines could go through several configuration cycles depending on contextual and contingent factors. At Alphasource, this was especially evident when we asked to describe changes, if any, occurred to the organizational processes and routines after the initial change and implementation effort. Depending on the department or team they belonged, participants 
Postprint version of:

Mariano, S., \& Al-Arrayed, S. (2018). Combinations of absorptive capacity metaroutines: the role of organizational disruptions and time constraints. European Management Journal, 36(2), 171-182. https://doi.org/10.1016/i.emj.2017.03.003

recalled slightly different time frames, ranging from 3 months to 1 year, and included descriptions of different steps occurred to have everything fixed and functional, which was a clear sign of existing organizational asymmetries:

"It changed around three times" (P18, Supervisor).

"It took us [Client Service Department] almost 6 months to have things running somewhat back to normal. However, after 6 months, we had to stop for another month. This, I believe, was due to several errors within the system that needed to be modified, so the whole process took us almost one full year, and one long year I must admit" (P6, Manager).

"I took, I am not sure, but I think it took 6 months for everything to be running smoothly" (P8, Employee).

"Each department had their own issues, paperwork, and requirements to amend in order to adapt with the new implemented process" (P10, Employee).

Another aspect that caught our attention regarded the several adjustment stages that the organization had to experience before new routines were effectively put in place, which made us consider a process that was all but linear and held certain degrees of cumulativeness in its internal mechanisms:

"The process went through several trial and error stages to get where it is now, but it did not change in the literal meaning of change" (P2, Manager).

"We did have to make amendments every few months if not monthly" (P3, Manager).

"There were some modifications added to the system" (P9, Employee).

"The process as a whole did not change but amendments were made along the way" (P10, Employee).

"The process had amendments put in, to modify the new process itself. These amendments took place about five times to have everything running smoothly once again" (P11, Employee).

\section{Discussion}

In the following sections, we discuss how our research findings enrich existing theoretical and empirical contributions in the current absorptive capacity debate. In addition, 
Postprint version of:

Mariano, S., \& Al-Arrayed, S. (2018). Combinations of absorptive capacity metaroutines: the role of organizational disruptions and time constraints. European Management Journal, 36(2), 171-182. https://doi.org/10.1016/i.emi.2017.03.003

we provide theoretical propositions, discuss managerial implications, and offer future research suggestions.

\subsection{Theoretical discussion and propositions}

Our research study primarily builds upon and expands the work of Lewin et al. (2011), although it provides some additional contributions to current absorptive capacity debates (Cohen \& Levinthal, 1989, 1990; Zahra \& George, 2002; Todorova \& Durisin, 2007; Ali et al., 2016; Ferreras-Mendez et al., 2016). It proposes potential refined factors that may directly or indirectly influence absorptive capacity metaroutines in organizational contexts. These factors appear to relate to the magnitude of organizational disruptions and time constraints, which our data suggest to be amplified by the intensity of required change for innovation adoption and the persistence of outcome, and the degree of involvement and cohesiveness of organizational members.

Intensity of required change for innovation adoption seemed to relate to organizational interdependencies and to the amount of replacements necessary to guarantee organizational change. At Alphasource, these replacements appeared to occur across all departments, although the work of the Technological Development Department seemed to contribute the most, especially with regard to the creation of internal interdependencies. Previous research has addressed the key role of stable patterns of interactions and collaboration among partners in firm alliances and has highlighted collaboration intensity and mutual obligations as two important determinants at the interorganizational level (Zollo, Reuer \& Singh, 2002). Our study adds to this research from an organizational-level perspective and provides a means to better understand how internal mechanisms of absorptive capacity may support internal replacements and create interdependencies. It sheds some initial lights on "the complexities associated with coordinating interdependencies and achieving complementarities between and among internal and external AC routines [which] remains to be explored" (Lewin et al., 2011, p. 94).

Persistence of outcomes described the duration of planned interventions to solve current disruptions and to ensure long-lasting results. Previous research has theorized that organizations tend to survive in the long term when internal change rates exceed external rates (Anderson, 1999; Lewin \& Volberda, 1999). Our findings seem to suggest that organizational long-lasting results may also relate to how organizations attend unexpected crises and promote supporting interdependencies at the internal metaroutines level to enhance 
Postprint version of:

Mariano, S., \& Al-Arrayed, S. (2018). Combinations of absorptive capacity metaroutines: the role of organizational disruptions and time constraints. European Management Journal, 36(2), 171-182. https://doi.org/10.1016/i.emi.2017.03.003

the absorption of new knowledge. In our research setting, this was especially evident when Alphasource coordinated simultaneous actions at different department levels to strengthen joined effort and ensure complete implementation cycles (Diedrich \& Guzman, 2015), for instances, when the actions of the Technology Development Department were propaedeutic to those of Client Service or Accounting Departments. These findings thus provide a more nuanced description of internal microlevel factors that may relate to absorptive capacity capabilities and offer some preliminary insights to be investigated in fruitful future research studies. Therefore, we propose the following:

Proposition 1: Intensity of required change for innovation adoption and persistence of outcomes are likely to relate to the magnitude of organizational disruptions that an organization may experience during periods of crises and are likely to describe the efforts required in the absorption of new organizational knowledge.

Degree of involvement appeared to describe the effort that single individuals performed to absorb new knowledge. Previous research studies have long explored how organizations promote knowledge absorption and sharing practices, pointing out the role of incentives (Baldwin, Magjuka \& Loher, 1991), punishments (Michailova \& Husted, 2003), cultural norms and values (Harrington \& Guimaraes, 2005), and the use of objects or artifacts (Cacciatori, 2012; Mariano \& Awazu, 2016), among others. Our findings, although seemed to confirm the key role of individuals in knowledge absorption processes, did not provide specific support for theorizations of mediating factors, such as incentives, punishments, and cultural and material aspects. At Alphasource, participants did not recall examples of such factors but showed a genuine support for corrective actions to guarantee organizational reputation and, ultimately, to survival. This insight adds to Lewin et al.'s (2011) theorizations at the level of sociocultural values, norms, and mechanisms that were out of our research scope but that could be further investigated.

In addition, our findings suggest that cohesiveness - described as the collective effort shown at the mesolevel by organizational members - has a direct influence on the likelihood of successful knowledge absorption practices. This empirical evidence seems to add to those previous studies exploring the benefits of cross-functional teams practice (Song, MontoyaWeiss \& Schmidt, 1997) and to studies investigating the relationship between absorptive capacity and knowledge value in project-based contexts (Yoo, Vonderembse \& Ragu-Nathan, 2011). It would be interesting to further explore the link between micro- and mesolevels in 
Postprint version of:

Mariano, S., \& Al-Arrayed, S. (2018). Combinations of absorptive capacity metaroutines: the role of organizational disruptions and time constraints. European Management Journal, 36(2), 171-182. https://doi.org/10.1016/i.emi.2017.03.003

the emergence and implementation of absorptive capacity metaroutines because our findings suggest the coexistence of both levels as supplements to the macrolevel. Therefore, we propose the following:

Proposition 2: Degree of involvement and cohesiveness of organizational members are likely to relate to time-varying boundary conditions that seem to have a direct influence on the composition of absorptive capacity metaroutines in organizational contexts.

Finally, our findings suggest that the combination of absorptive capacity metaroutines may experience internal asymmetries and be cumulative in nature. Asymmetries may suggest the existence of different absorption rates at different department or group levels and may vary depending on internal or external contingencies. Therefore, corresponding metaroutines may be subjected to changes and experience accumulation or removal of certain routines overtime. Similarly, the apparent cumulative nature of absorptive capacity may suggest the existence of adjustment cycles that, in the long term, can contribute to desired outcomes, similarly to existing knowledge shaping theorizations (Mariano \& Casey, 2016). Previous research highlighted the benefits of accumulated knowledge and experience that reduce organizational change costs (Zander \& Kogut, 1995; Teece et al., 1997). Our findings suggest that accumulation of new knowledge may manifest not only as external absorption practices but also may relate to internal metaroutines that emerge and modify depending on intervening variables such as disruptions (see also Lev, Fiegenbaum \& Shoham, 2009) or time constraints and confirm the path-dependent tendency of absorptive capacity (Cohen \& Levinthal, 1990; Zahra \& George, 2002). These findings add to previous studies discussing the crucial role of feedback loops (Todorova \& Durisin, 2007), debating the multidimensional nature of the construct (Daspit \& D’Souza, 2013), or distinguishing between its potential and realized capacity (Zahra \& George, 2002; see also Cegarra-Navarro, Eldridge \& Wensley, 2014; Andersén \& Kask, 2012; Ben-Oz \& Greve, 2012; Kang \& Lee, 2016). Therefore, we propose the following:

Proposition 3: Absorptive capacity metaroutines are likely to experience a certain level of asymmetries within organizational contexts and show incremental and cumulative features.

It is safe to say that the peculiarity of our research setting may have determined these specific combinations, determinants, and actions. We may intuitively believe that other 
Postprint version of:

Mariano, S., \& Al-Arrayed, S. (2018). Combinations of absorptive capacity metaroutines: the role of organizational disruptions and time constraints. European Management Journal, 36(2), 171-182. https://doi.org/10.1016/i.emi.2017.03.003

organizational contexts could potentially display different combinations of metaroutines. Therefore, we speculate that a fruitful way to study absorptive capacity metaroutines may consider the magnitude of experienced organizational disruptions, defined by how much these disruptions manifest themselves (intensity) and how long they last (persistence). In summary, we speculate that internal or external organizational disruptions may trigger absorptive capacity and force organizations to find innovative solutions within certain time boundary conditions, taking into account individual and group efforts. We also speculate that the magnitude of these disruptions may be defined by how intense these disruptions are and how long their outcomes persist over time. On the basis of our empirical findings, we reasonably believe that the magnitude of organizational disruptions and time constraints may help explain why certain configurations of absorptive capacity metaroutines emerge and what interdependencies and complementarities may surface and relate to them. Therefore, we propose the following:

Proposition 4: Magnitude of organizational disruptions and time constraints are likely to help explain the emergence, interdependence, and complementarities among absorptive capacity metaroutines in organizational contexts.

\subsection{Managerial discussion}

From a managerial perspective, this study sheds some light on the existence of asymmetries in the knowledge absorption process and the cumulative nature of absorptive capacity outcomes.

These findings advise managers to pay close attention to where these asymmetries reside within organizational contexts, to reduce irregularities in exploitative practices, and to enhance continuous improvements. In turn, these practices would increase opportunities for knowledge absorption to take place at individual and group levels and would enable the achievement of planned change at the organizational level.

\section{Limitations and future research directions}

This study has limitations connected to contingency factors and organization-specific phenomena and boundary conditions related to firm size and age and cultural contexts. Another limitation is regarding the exclusion of moderating variables such as sociocultural values, norms, and mechanisms (Lewin et al., 2011) that were out of our research scope from the analysis. 
Postprint version of:

Mariano, S., \& Al-Arrayed, S. (2018). Combinations of absorptive capacity metaroutines: the role of organizational disruptions and time constraints. European Management Journal, 36(2), 171-182. https://doi.org/10.1016/i.emi.2017.03.003

Future research should be conducted to investigate some of our proposed interpretations. For instance, we proposed that organizational disruptions trigger absorptive capacity. Further empirical studies could investigate the extent to which this interpretation applies to different organizational contexts or industries. Further research could also investigate the extent to which variables such as intensity of required change for innovation adoption and persistence of outcomes explain alone the emergence of certain metaroutines and organization-specific routines or may combine with additional and more refined variables. Another fruitful research area may regard the analysis of temporal dimensions and boundary conditions - that we explained under the "time constraints" factor - to investigate the extent to which individual contributions and group cohesiveness may be influenced by the passage of time. This is a prominent direction for future research because it is still not clear how dynamic capabilities tend to change over time or how organizational routines are influenced by transactive memory systems (Argote \& Ren, 2012; Argote \& Miron-Spektor, 2011). Future research could explore the extent to which some of our proposed factors may apply within different organizational contexts where, for instances, flat organizational structures promote self-organized practices. Although our findings did not provide more granular descriptions of determinants influencing high cohesiveness levels, nor was this an explicit scope of our research study, we believe that the link among the micro-, meso-, and macrolevel and the connection with metaroutines and organization-specific routines may also represent a fruitful area for future investigations. Finally, future studies could operationalize our proposed variables and empirically test them through the use of quantitative approaches such as survey methods.

\section{Conclusions}

We explored absorptive capacity metaroutines in a financial organization. We discovered that magnitude of organizational disruptions and time constraints influenced absorptive capacity internal and external metaroutines. Intensity of required change for innovation adoption and persistence of outcomes related to the magnitude of organizational disruptions, while degree of involvement and cohesiveness of organizational members related to the time constraints factor. In addition, we found that the combination of absorptive capacity metaroutines experienced a certain level of asymmetries and had incremental and cumulative features. Our findings extend current theorizations of absorptive capacity metaroutines and give preliminary directions to explain why some combinations of 
Postprint version of:

Mariano, S., \& Al-Arrayed, S. (2018). Combinations of absorptive capacity metaroutines: the role of organizational disruptions and time constraints. European Management Journal, 36(2), 171-182. https://doi.org/10.1016/i.emi.2017.03.003

metaroutines appear to be superior to others. We believe that our investigation offers fruitful directions to future studies on the microfoundations of absorptive capacity.

\section{References}

Ali, M., Kan, K. A. S., \& Sarstedt, M. (2016). Direct and configurational paths of absorptive capacity and organizational innovation to successful organizational performance. Journal of Business Research, 69(11), 5317-5323.

Andersén, J., \& Kask, J. (2012). Asymmetrically realized absorptive capacity and relationship durability. Management Decision, 50(1), 43-57.

Anderson, P. (1999). Perspective: Complexity theory and organization science. Organization Science, 10(3), 216-232.

Argote, L., \& Miron-Spektor, E. (2011). Organizational learning: From experience to knowledge. Organization Science, 22(5), 1123-1137.

Argote, L., \& Ren, Y. (2012). Transactive memory systems: A microfoundation of dynamic capabilities. Journal of Management Studies, 49(8), 1375-1382.

Autio, E., Sapienza, H. J., \& Almeida, J. G. (2000). Effects of age at entry, knowledge intensity, and imitability on international growth. Academy of Management Journal, 43(5), 909-924.

Baldwin, T. T., Magjuka, R. J., \& Loher, B. T. (1991). The perils of participation: Effects of choice of training on trainee motivation and learning. Personnel Psychology, 44(1), 51-65.

Barkema, H. G., \& Vermeulen, F. (1998). International expansion through start-up or acquisition: A learning perspective. Academy of Management Journal, 41(1), 7-26.

Belderbos, R., Gilsing, V. A., \& Suzuki, S. (2015). Direct and mediated ties to universities: "Scientific" absorptive capacity and innovation performance of pharmaceutical firms. Strategic Organization, 14(1), 32-52.

Ben-Oz, C., \& Greve, H. R. (2012). Short-and long-term performance feedback and absorptive capacity. Journal of Management, 41(7), 1827-1853.

Berger,P. L., \& Luckman, T. (1966). The social construction of reality. London: Penguin 
Bilgili, T. V., Kedia, B. L., \& Bilgili, H. (2016). Exploring the influence of resource environments on absorptive capacity development: The case of emerging market firms. Journal of World Business, 51(5), 700-712.

Brettel, M., Greve, G. I., \& Flatten, T. C. (2011). Giving up linearity: Absorptive capacity and performance. Journal of Managerial Issues, 23(2), 164-189.

Cacciatori, E. (2012). Resolving conflict in problem-solving: Systems of artefacts in the development of new routines. Journal of Management Studies, 49(8), 1559-1585.

Cegarra-Navarro, J. G., Eldridge, S., \& Wensley, A. K. (2014). Counter-knowledge and realised absorptive capacity. European Management Journal, 32(2), 165-176.

Cepeda-Carrion, I., Leal-Millán, A. G., Martelo-Landroguez, S., \& Leal-Rodriguez, A. L. (2016). Absorptive capacity and value in the banking industry: A multiple mediation model. Journal of Business Research, 69(5), 1644-1650.

Cockburn, I. M., \& Henderson, R. M. (1998). Absorptive capacity, coauthoring behavior, and the organization of research in drug discovery. The Journal of Industrial Economics, 46(2), 157-182.

Cohen, M. D. (1991). Individual learning and organizational routine: Emerging connections. Organization Science, 2(1), 135-139.

Cohen, W. M., \& Levinthal, D. A. (1989). Innovation and learning: The two faces of R\&D. The Economic Journal, 99(397), 569-596.

Cohen, W. M., \& Levinthal, D. A. (1990). Absorptive capacity: A new perspective on learning and innovation. Administrative Science Quarterly, 35(1), 128-152.

Creswell, J. (2009). Research design: Qualitative, quantitative, and mixed methods approaches. Thousand Oaks, CA: Sage Publications.

Daspit, J. J., \& D'Souza, D. E. (2013). Understanding the multi-dimensional nature of absorptive capacity. Journal of Managerial Issues, 25(3), 299-316.

Denford, J. S. (2013). Building knowledge: Developing a knowledge-based dynamic capabilities typology. Journal of Knowledge Management, 17(2), 175-194. 
Denicolai, S., Ramirez, M., \& Tidd, J. (2016). Overcoming the false dichotomy between internal R\&D and external knowledge acquisition: Absorptive capacity dynamics over time. Technological Forecasting and Social Change, 104, 57-65.

Diedrich, A., \& Guzman, G. (2015). From implementation to appropriation: Understanding knowledge management system development and introduction as a process of translation. Journal of Knowledge Management, 19(6), 1273-1294.

Easterby-Smith, M., Thorpe, R., \& Jackson, P. R. (2012). Management Research. Thousand Oaks, CA: Sage Publications.

Eisenhardt, K. M. (1989). Building theories from case study research. Academy of Management Review, 14(4), 532-550.

Eisenhardt, K. M., \& Graebner, M. E. (2007). Theory building from cases: Opportunities and challenges. Academy of Management Journal, 50(1), 25-32.

Eisenhardt, K. M., \& Martin, J. A. (2000). Dynamic capabilities: What are they? Strategic Management Journal, 21(10-11), 1105-1121.

Ferreras-Méndez, J. L., Fernández-Mesa, A., \& Alegre, J. (2016). The relationship between knowledge search strategies and absorptive capacity: A deeper look. Technovation, 54, $48-61$.

Flanagan, J. C. (1954). The critical incident technique. Psychological Bulletin, 51(4), 327.

Flatten, T. C., Engelen, A., Zahra, S. A., \& Brettel, M. (2011). A measure of absorptive capacity: Scale development and validation. European Management Journal, 29(2), 98116.

Gebauer, H., Worch, H., \& Truffer, B. (2012). Absorptive capacity, learning processes and combinative capabilities as determinants of strategic innovation. European Management Journal, 30(1), 57-73.

Gersick, C. J., \& Hackman, J. R. (1990). Habitual routines in task-performing groups. Organizational Behavior and Human Decision Processes, 47(1), 65-97.

Habermas, J. (1970). Knowledge and interest. In Emmett D., \& A. Macintyre (eds.), Sociological theory and philosophical analysis. London: Macmillan, pp. 36-54. 
Mariano, S., \& Al-Arrayed, S. (2018). Combinations of absorptive capacity metaroutines: the role of organizational disruptions and time constraints. European Management Journal, 36(2), 171-182. https://doi.org/10.1016/i.emi.2017.03.003

Harrington, S. J., \& Guimaraes, T. (2005). Corporate culture, absorptive capacity and IT success. Information and Organization, 151, 39-63.

Helfat, C. E. (1997). Know-how and asset complementarity and dynamic capability accumulation: The case of R\&D. Strategic Management Journal, 18(5), 339-360.

Helfat, C. E., Finkelstein, S., Mitchell, W., Peteraf, M., Singh, H., Teece, D., \& Winter, S. G. (2009). Dynamic capabilities: Understanding strategic change in organizations. Oxford: Blackwell Publishing.

Hill, C. W., \& Rothaermel, F. T. (2003). The performance of incumbent firms in the face of radical technological innovation. Academy of Management Review, 28(2), 257-274.

Hurmelinna-Laukkanen, P., Olander, H., Blomqvist, K., \& Panfilii, V. (2012). Orchestrating R\&D networks: Absorptive capacity, network stability, and innovation appropriability. European Management Journal, 30(6), 552-563.

Inkpen, A. (1998). Learning, knowledge acquisition, and strategic alliances. European Management Journal, 16(2), 223-229.

Jansen, J. J., Van Den Bosch, F. A., \& Volberda, H. W. (2005). Managing potential and realized absorptive capacity: How do organizational antecedents matter? Academy of Management Journal, 48(6), 999-1015.

Jick, T. D. (1979). Mixing qualitative and quantitative methods: Triangulation in action. Administrative Science Quarterly, 24(4), 602-611.

Kang, M., \& Lee, M. J. (2016). Absorptive capacity, knowledge sharing, and innovative behaviour of R\&D employees. Technology Analysis \& Strategic Management, 1-14.

Kim, B., Kim, E., \& Foss, N. J. (2016). Balancing absorptive capacity and inbound open innovation for sustained innovative performance: An attention-based view. European Management Journal, 34(1), 80-90.

Knoppen, D., Sáenz, M. J., \& Johnston, D. A. (2011). Innovations in a relational context: Mechanisms to connect learning processes of absorptive capacity. Management Learning, 42(4), 419-438. 
Koza, M., A. Y. Lewin. (1998). The co-evolution of strategic alliances. Organization Science, 9(3), 255-264.

Lane, P. J., Koka, B. R., \& Pathak, S. (2006). The reification of absorptive capacity: A critical review and rejuvenation of the construct. Academy of Management Review, 31(4), $833-863$.

Lane, P. J., M. Lubatkin. (1998). Relative absorptive capacity and interorganizational learning. Strategic Management Journal, 19(5), 461-477.

Latour, B., \& Woolgar, S. (1979). Laboratory life: The social construction of scientific facts. Beverly Hills, CA: Sage

Lev, S., Fiegenbaum, A., \& Shoham, A. (2009). Managing absorptive capacity stocks to improve performance: Empirical evidence from the turbulent environment of Israeli hospitals. European Management Journal, 27(1), 13-25.

Levitt, B., J. G. March. (1988). Organizational learning. Annual Review of Sociology, 14, 319-340.

Lewin, A. Y., H. Volberda. (1999). Prolegomena on coevolution: A frame-work for research on strategy and new organizational forms. Organization Science, 10(5) 519-534

Lewin, A. Y., Massini, S., \& Peeters, C. (2011). Microfoundations of internal and external absorptive capacity routines. Organization Science, 22(1), 81-98.

Lewin, A. Y., S. Massini. (2003). Knowledge creation and organizational capabilities of innovating and imitating firms. In H. Tsoukas, \& N. Mylonopoulos, (eds). Organizations as Knowledge Systems: Knowledge, Learning and Dynamic Capabilities (pp. 209-237). New York: Palgrave/Macmillan.

Lichtenthaler, U., \& Lichtenthaler, E. (2009). A capability-based framework for open innovation: Complementing absorptive capacity. Journal of Management Studies, 46(8), $1315-1338$.

Lichtenthaler, U. (2016). Absorptive capacity and firm performance: An integrative framework of benefits and downsides. Technology Analysis \& Strategic Management, 28(6), 664-676. 
Mariano, S., \& Al-Arrayed, S. (2018). Combinations of absorptive capacity metaroutines: the role of organizational disruptions and time constraints. European Management Journal, 36(2), 171-182. https://doi.org/10.1016/i.emi.2017.03.003

Lincoln, Y. S., \& Guba, E. G. (1985). Naturalistic inquiry. Thousand Oaks, CA: Sage Publications.

Louis, M. R., R. I. Sutton. (1991). Switching cognitive gears: From habits to mind to active thinking. Human Relations, 44(1), 55-76.

Mariano, S. (2013). Understanding the nature of knowledge: An empirical study of knowledge sharing in a knowledge intensive organisation. International Journal of Learning and Intellectual Capital, 10(2), 151-164.

Mariano, S., \& Awazu, Y. (2016). Artifacts in knowledge management research: A systematic literature review and future research directions. Journal of Knowledge Management, 20(6), 1333-1352.

Mariano, S., \& Casey, A. (2015). Is organizational innovation always a good thing? Management Learning, 46(5), 530-545.

Mariano, S., \& Casey, A. (2016). The dynamics of organizational routines in a startup: The EREDA model. European Management Review, 13(4), 251-274.

Mariano, S., \& Walter, C. (2015). The construct of absorptive capacity in knowledge management and intellectual capital research: Content and text analyses. Journal of Knowledge Management, 19(2), 372-400.

Marshall, M. N. (1996). The key informant technique. Family Practice, 13(1), 92-97.

Martinkenaite, I., \& Breunig, K. J. (2016). The emergence of absorptive capacity through micro-macro level interactions. Journal of Business Research, 69(2), 700-708.

Merriam, S.B. (2001). Qualitative research and case study applications in education. San Francisco, CA: Jossey-Bass.

Michailova, S., \& Husted, K. (2003). Knowledge-sharing hostility in Russian firms. California Management Review, 453, 59-77.

Miles, M. B. and Huberman, A. M. (1994). Qualitative data analysis: A sourcebook of new methods. Newbury Park, CA: Sage Publications.

Mowery, D. C., \& Oxley, J. E. (1995). Inward technology transfer and competitiveness: The role of national innovation systems. Cambridge Journal of Economics, 19(1), 67-93. 
Nelson, R. R., \& Winter, S. G. (1982). An evolutionary theory of economic change.

Cambridge, MA: Belknap Press/Harvard University Press.

Patton, M.Q. (2002). Qualitative research and evaluation methods. Thousand Oaks, CA: Sage Publications.

Peeters, C., Massini, S., \& Lewin, A. Y. (2014). Sources of variation in the efficiency of adopting management innovation: The role of absorptive capacity routines, managerial attention and organizational legitimacy. Organization Studies, 35(9), 1343-1371.

Postrel, S., R. Rumelt. (1992). Incentives routines and self-command. Industrial and Corporate Change, 1, 397-425.

Roberts, N., Galluch, P., Dinger, M. and Grover, V. (2012). Absorptive capacity and information systems research: Review, synthesis, and directions for future research. MIS Quarterly, 36(2), 625-648.

Rossman, G. B., \& Rallis, S. F. (1998). Learning in life: An introduction to qualitative research. Thousand Oaks, CA: Sage.

Rubin H. J., \& Rubin, I. S. (1995). Qualitative interviewing: The art of hearing data. Thousand Oaks, CA: Sage Publications.

Sciascia, S., D’Oria, L., Bruni, M., \& Larrañeta, B. (2014). Entrepreneurial Orientation in low-and medium-tech industries: The need for Absorptive Capacity to increase performance. European Management Journal, 32(5), 761-769.

Seale, C. (1999). Quality in qualitative research. Qualitative Inquiry, 5(4), 465-478.

Senivongse, C., Mariano, S., \& Bennet, A. (2015). Internal Processes of Absorptive Capacity: A Systematic Literature Review and Future Research Directions. Proceedings of the International Conference on Intellectual Capital and Knowledge Management and Organizational Learning (p. 222).

Shotter, J. (1993). Conversational realities. London: Sage.

Simonin, B. L. (1999). Ambiguity and the process of knowledge transfer in strategic alliances. Strategic Management Journal, 20(7), 595-623. 
Mariano, S., \& Al-Arrayed, S. (2018). Combinations of absorptive capacity metaroutines: the role of organizational disruptions and time constraints. European Management Journal, 36(2), 171-182. https://doi.org/10.1016/i.emj.2017.03.003

Song, X. M., M. M. Montoya-Weiss, J. B. Schmidt. (1997). Antecedents and consequences of cross-functional cooperation: A comparison of $\mathrm{R} \& \mathrm{D}$, manufacturing and marketing perspectives. Journal of Product Innovation Management, 14(2), 35-47.

Stake, R. E. (1995). The art of case study research. Thousand Oaks, CA: Sage Publications.

Sun, P. (2010). Five critical knowledge management organizational themes. Journal of Knowledge Management, 14(4), 507-523.

Szulanski, G. (1996). Exploring internal stickiness: Impediments to the transfer of best practice within the firm. Strategic Management Journal, 17 (Winter Special Issue), 27-43.

Teece, D.J., Pisano, G., \& Shuen, A. (1997), Dynamic capabilities and strategic management. Strategic Management Journal, 18(7), 509-533.

Todorova, G., \& Durisin, B. (2007). Absorptive capacity: Valuing a reconceptualization. Academy of Management Review, 32(3), 774-786.

Tsai, K. H., \& Yang, S. Y. (2015). How absorptive capacity moderates the value of firm innovativeness in turbulent markets. Canadian Journal of Administrative Sciences/Revue Canadienne des Sciences de l'Administration, DOI: 10.1002/cjas.1352.

Tseng, C.Y., Pai, D.C., \& Hung, C.H. (2011). Knowledge absorptive capacity and innovation performance in KIBS. Journal of Knowledge Management, 15(6), 971-983.

Van den Bosch, F. A. J., Volberda, H.W., \& de Boer, M. (1999). Coevolution of firm absorptive capacity and knowledge environment: Organizational forms and combinative capabilities. Organization Science, 10(5), 551-568.

van der Heiden, P., Pohl, C., Mansor, S., \& van Genderen, J. (2016). Necessitated absorptive capacity and metaroutines in international technology transfer: A new model. Journal of Engineering and Technology Management, 41, 65-78.

Veugelers, R. (1997). Internal R\&D expenditures and external technology sourcing. Research Policy, 26(3), 303-316.

Volberda, H. W., Foss, N. J., \& Lyles, M. A. (2010). Perspective-absorbing the concept of absorptive capacity: How to realize its potential in the organization field. Organization Science, 21(4), 931-951. 
Mariano, S., \& Al-Arrayed, S. (2018). Combinations of absorptive capacity metaroutines: the role of organizational disruptions and time constraints. European Management Journal, 36(2), 171-182. https://doi.org/10.1016/i.emj.2017.03.003

Weiss, H. M., \& Ilgen, D. R. (1985). Routinized behavior in organizations. Journal of Behavioral Economics, 14, 57-67.

Yoo, D.K., Vonderembse, M.A., \& Ragu-Nathan, T. S. (2011). Knowledge quality: Antecedents and consequence in project teams. Journal of Knowledge Management, 15(2), $329-343$.

Zahra, S., \& George, G. (2002). Absorptive capacity: A review, reconceptualization, and extension. Academy of Management Review, 27(2), 185-2003.

Zander, U., \& Kogut, B. (1995). Knowledge and the speed of the transfer and imitation of organizational capabilities: An empirical test. Organization Science, 6(1), 76-92.

Zollo, M., \& Winter, S. G. (2002). Deliberate learning and the evolution of dynamic capabilities. Organization Science, 13(3), 339-351.

Zollo, M., Reuer, J. J., \& Singh, H. (2002). Interorganizational routines and performance in strategic alliances. Organization Science, 13(6), 701-713. 
Postprint version of:

Mariano, S., \& Al-Arrayed, S. (2018). Combinations of absorptive capacity metaroutines: the role of organizational disruptions and time constraints. European Management Journal, 36(2), 171-182. https://doi.org/10.1016/j.emj.2017.03.003

Table 1 - Demographics of Participants

\begin{tabular}{|l|l|l|l|}
\hline Participant & Role & $\begin{array}{l}\text { Gende } \\
\text { r }\end{array}$ & $\begin{array}{l}\text { Follow-up } \\
\text { Interview }\end{array}$ \\
\hline P1 & Manager (Key Informant) & M & Yes \\
\hline P2 & Manager & F & Yes \\
\hline P3 & Manager & M & Yes \\
\hline P4 & Manager & M & Yes \\
\hline P5 & Manager & M & Yes \\
\hline P6 & Manager & F & - \\
\hline P7 & Manager & M & - \\
\hline P8 & Employee & M & - \\
\hline P9 & Employee & M & - \\
\hline P10 & Employee & M & - \\
\hline P11 & Employee & M & - \\
\hline P12 & Employee & M & - \\
\hline P13 & Employee & F & - \\
\hline P14 & Employee & F & - \\
\hline P15 & Employee & M & - \\
\hline P16 & Employee & M & - \\
\hline P17 & Employee & M & - \\
\hline P18 & Employee (Supervisor) & M & - \\
\hline P19 & Employee & $\mathrm{M}$ & - \\
\hline P20 & Employee & F & - \\
\hline P21 & Employee & F & - \\
\hline & & \\
\hline
\end{tabular}


Mariano, S., \& Al-Arrayed, S. (2018). Combinations of absorptive capacity metaroutines: the role of organizational disruptions and time constraints. European Management Journal, 36(2), 171-182. https://doi.org/10.1016/j.emj.2017.03.003

Table 2 - Organization-specific Routines at Alphasource

\begin{tabular}{|c|c|c|}
\hline Organization-Specific Routines & Target & Description \\
\hline Introduction of audit sessions & Individuals & Internal and external investigations. Calling card-holders for verification \\
\hline Firing and hiring employees & Individuals & Processes are arranged by department heads/senior managers using protocols \\
\hline $\begin{array}{l}\text { Introduction of fraud prevention } \\
\text { training courses }\end{array}$ & Individuals & Mandatory attendance of relevant staff related to fraud prevention training courses \\
\hline Introduction of training sessions & Individuals & Training sessions introduced for each department. Average duration: 1 week \\
\hline $\begin{array}{l}\text { Introduction of job rotation } \\
\text { mechanisms }\end{array}$ & Individuals & Rotation of employees depending on business requirements \\
\hline Credit cards issuing/replacing & Products & Benchmarking more sophisticated systems. Daily process. Average delivery time: One day \\
\hline Implementation of new IT system & Processes & Upgrading of system made within a working day to avoid disruptions \\
\hline Introduction of new manual & Processes & Distribution of hard copies \\
\hline $\begin{array}{l}\text { Handling inquiries from current } \\
\text { customers }\end{array}$ & Processes & $\begin{array}{l}\text { Handled by front office team and call center. Quality measured by average service time kept within ten minutes } \\
\text { for walking-in customers and lesser for phone calls }\end{array}$ \\
\hline Testing of prototypes & Processes & Testing of credit card prototypes with internal employees \\
\hline Introduction of monitoring system & Processes & Monitoring is being held constantly (24/7) to detect unusual behavior \\
\hline Fixing of bugs and glitches & Processes & Handled by the Information Technology Development department. Handling average time: Not exceed 24 hours \\
\hline Attracting new customers & Processes & Social media, boards, promotions, and special offers are used to attract new customers \\
\hline
\end{tabular}


Mariano, S., \& Al-Arrayed, S. (2018). Combinations of absorptive capacity metaroutines: the role of organizational disruptions and time constraints. European Management Journal, 36(2), 171-182. https://doi.org/10.1016/j.emj.2017.03.003

\begin{tabular}{|l|l|l|}
\hline & & \\
\hline Arrangement of audit follow-up & Processes & Carried out by department heads to implement corrective actions \\
\hline
\end{tabular}

Table 3 - AC Metaroutines and Organization-specific Routines at Alphasource

\begin{tabular}{|c|c|c|c|}
\hline & & Organization-specific Routines at Alphasource & Exemplars from Interview Transcripts \\
\hline \multirow{6}{*}{ 㟒 } & Facilitating variation & Not emerged & 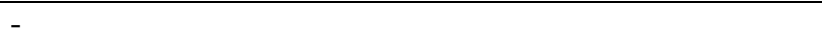 \\
\hline & Internal selection regimes & Testing of credit card prototypes done by employees & $\begin{array}{l}\text { - "We first applied it on staff members' credit cards to } \\
\text { see if there were any glitches that needed to be } \\
\text { amended before putting it out to customers and having } \\
\text { to deal with it" (P3, Manager) }\end{array}$ \\
\hline & \multirow[t]{3}{*}{$\begin{array}{l}\text { Sharing knowledge and superior } \\
\text { practices across the organization }\end{array}$} & Implementation of new information technology system & $\begin{array}{l}\text { - "The Technology Development Department [fictional } \\
\text { name] had to build the new IT system for the whole } \\
\text { organization due to the fraud detection problem" (P5, } \\
\text { Manager) }\end{array}$ \\
\hline & & Introduction of new manual & $\begin{array}{l}\text { - "The easy step-by-step guide helped us quite a bit" } \\
\text { (P10, Employee) } \\
\text { - "The user manual was more than satisfying as it had all } \\
\text { the steps required if we struggled with anything" (P11, } \\
\text { Employee) }\end{array}$ \\
\hline & & Introduction of job rotation mechanisms & $\begin{array}{l}\text { - "Another requirement with the change process was to } \\
\text { have employees rotate through departments and roles } \\
\text { very } 4 \text { weeks" (P3, Manager) } \\
\text { - "Oh yes, as I mentioned earlier that we had to follow } \\
\text { this new procedure of job rotation, which we received } \\
\text { several complaints from various departments" (P4, } \\
\text { Manager) } \\
\text { "Top management announced job rotation every } 4 \\
\text { weeks" (P6, Manager, Follow-up) }\end{array}$ \\
\hline & Reflection, updating, and replication & Introduction of audit sessions & $\begin{array}{l}\text { - "Top management had to undergo an investigation of } \\
\text { how the fraud took place and where the glitches were } \\
\text { in the system" (P1, Manager) } \\
\text { - "The difficult part was the intensive auditing our }\end{array}$ \\
\hline
\end{tabular}


Mariano, S., \& Al-Arrayed, S. (2018). Combinations of absorptive capacity metaroutines: the role of organizational disruptions and time constraints. European Management Journal, $36(2), 171-182$.

https://doi.org/10.1016/j.emj.2017.03.003

\begin{tabular}{|c|c|c|c|}
\hline & & & $\begin{array}{l}\text { department had to undergo every quarter of the year" } \\
\text { (P2, Manager) }\end{array}$ \\
\hline & & Introduction of monitoring system & $\begin{array}{l}\text { - "My team had to monitor our clients' accounts on a } \\
\text { weekly basis in order to have early notice of any } \\
\text { suspicious activities" (P1, Manager, Follow-up) }\end{array}$ \\
\hline & & Credit cards issuing/replacing & $\begin{array}{l}\text { "The whole system of credit cards that we were using } \\
\text { had to be changed, and we offered a new type of card } \\
\text { to our customers, which carried a chip in it and offered } \\
\text { more security" (P3, Manager) }\end{array}$ \\
\hline & & Fixing of bugs and glitches & $\begin{array}{l}\text { - "There were several glitches in the system that needed } \\
\text { to be adjusted" (P5, Manager) } \\
\text { - "The reason for these changes were to amend the } \\
\text { glitches and gaps within the system" (P12, Employee) }\end{array}$ \\
\hline & & Arrangement of follow-up audit sessions & $\begin{array}{l}\text { - "We have constant visit by the external auditors every } \\
\text { quarter" (P2, Manager, Follow-up) }\end{array}$ \\
\hline \multirow[b]{2}{*}{ 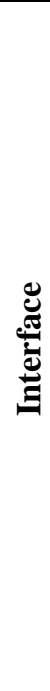 } & Managing adaptive tension & Handling inquiries from current customers & $\begin{array}{l}\text { - "This was very difficult to communicate to them } \\
\text { [customers] that we were facing some fraud issues. } \\
\text { This was quite risky from our side, and we feared the } \\
\text { loss of some of our loyal customers" (P1, Manager) } \\
\text { - "The most difficult learning aspect was communicating } \\
\text { the problem to our VIP customers in a way that would } \\
\text { not have them worried, of course" (P6, Manager) }\end{array}$ \\
\hline & $\begin{array}{l}\text { Transferring knowledge back to } \\
\text { the organization }\end{array}$ & Learning from external consultants & $\begin{array}{l}\text { - "Several staff members were sent to extensive training } \\
\text { - courses with partner companies" (P8, Employee) } \\
\text { "The training courses that employees received } \\
\text { individually helped with their learning knowledge to } \\
\text { adapt and apply it much faster than if these trainings } \\
\text { were attended by one specific person and then } \\
\text { cascaded to the rest of the team" (P10, Employee) } \\
\text { - "We had a special team of experts come in to the } \\
\text { company and help us create and amend the forms and } \\
\text { documents" (P1, Manager, Follow-up) }\end{array}$ \\
\hline
\end{tabular}


Mariano, S., \& Al-Arrayed, S. (2018). Combinations of absorptive capacity metaroutines: the role of organizational disruptions and time constraints. European Management Journal, $36(2), 171-182$. https://doi.org/10.1016/j.emj.2017.03.003

\begin{tabular}{|c|c|c|c|}
\hline & & Hiring new employees & $\begin{array}{l}\text { - "We also had to have new employees hired" (P1, } \\
\text { Manager) } \\
\text { - "To hire almost } 12 \text { new staff members" (P4, Manager) }\end{array}$ \\
\hline \multirow{4}{*}{ 宽 } & $\begin{array}{l}\text { Identifying and recognizing value of } \\
\text { externally generated knowledge }\end{array}$ & Not emerged & - \\
\hline & \multirow{3}{*}{$\begin{array}{l}\text { Learning from and with partners, } \\
\text { suppliers, customers, competitors, } \\
\text { and consultants }\end{array}$} & Networking to attract new customers & $\begin{array}{l}\text { - "We had to come up with a strategy of putting } \\
\text { ourselves back in the market" (P6, Manager) }\end{array}$ \\
\hline & & Introduction of fraud prevention training courses & $\begin{array}{l}\text { - "Employees took fraud courses within our department" } \\
\text { (P2, Manager) }\end{array}$ \\
\hline & & $\begin{array}{l}\text { Introduction of dedicated training sessions held by external } \\
\text { consultants }\end{array}$ & $\begin{array}{l}\text { - "All employees had to be trained to know the new and } \\
\text { updated regulations of the new chip cards that were } \\
\text { going to be issues. Client Service Department [fictional } \\
\text { name] had to undergo some training" (P1, Manager) } \\
\text { - "A positive change from the whole process would be } \\
\text { the training that employees received" (P2, Manager) } \\
\text { - "We had to send a large number of staff for training" } \\
\text { (P3, Manager) } \\
\text { - "...training that we had to offer to our staff" (P6, } \\
\text { Manager) }\end{array}$ \\
\hline
\end{tabular}




\section{APPENDIX A}

\section{Additional Evidence for Emerged Themes from Interviews Transcripts}

Subtheme $\quad$ Evidence

\section{Theme 1: Magnitude of Organizational Disruptions}

\footnotetext{
Intensity of required

change for

innovation adoption

- "Each stage was linked to the success of the other stage, and so if one stage failed, the next was sure to fail" (P2, Manager)

- "We had to work in a very fast pace in order to rectify the problem and minimize our losses as much as possible, so time was a crucial element for us" (P9, Employee)

- "Most employees understood the complexity of the situation the company was facing and had to be cooperative with the situation. Also employees had to work for several months manually, but they were very understanding even when they had to input the information into the system and faced several glitches" (P4, Manager, Follow-up)

Persistence of outcomes

- "All [new processes and routines] were introduced to ensure more security for future problems and for these problems to be minimized" (P5, Manager)

- “...hoping we don't have to face a situation as such in the future” (P2, Manager, Follow-up)
}

\section{Theme 2: Time Constraints}
Degree of
- "A lot of us worked overtime just to ensure that all would get back to normal once again" (P2, Manager)
involvement
- "It is the employees job to adapt to these changes and solve them, otherwise the company will collapse. Your workplace is your second home; you might even spend more time in it than your actual home" (P6, Manager)
- "They [the employees] were able to handle such difficult situations under tremendous pressure" (P12, Employee)
- "Everyone carried out his or her tasks in a very professional manner and were very efficient while carrying out their jobs" (P13, Employee)
Cohesiveness
- "All employees were cooperative toward what the company was going through and willing to help and support each other" (P4, Manager)
- "The support received from the IT staff was outstanding" and "They [heads of departments] were so organized with tasks, and the employees were very supportive" (P10, Employee)
- “...having a team that was understanding and willing to work under the pressure they were put in. They were very dedicated and learned the main 


Subtheme Evidence

procedures in an exceptional time" (P1, Manager, Follow-up)

- "All departments and staff were very cooperative" and "the whole organization with all the departments were willing to work together" (P4, Manager, Follow-up)

\section{Theme 3: Combinations of Absorptive Capacity Metaroutines}

Asymmetries

- "It took us [Accounting Department] almost a year to have everything on track" (P3, Manager)

- "It took us [Human Resources Department] almost a full year to have everything up and running like the old days" (P4, Manager)

- "It took our team [Technology Development Department] 6 months to have everything running and modified from the old system" (P5, Manager)

- "The process was amended six times during the past year" (P12, Employee)

Cumulativeness

- "There were major enhancements for each process" and "There were adjustments during each stage but not major ones" (P2, Manager)
- "These changes had to be modified every few months" and "Also, today in the Technology Development Department, I can say that problem solving issues with this new system have decreased 70\%" (P5, Manager)

- "There are always improvements being put to the system for extra security" and "Our campaign changed on a monthly basis as we had to include or omit certain requirements" (P6, Manager)

- "For the process to take place, it took almost 6 months, but for the whole process to be up and running, it took 12 months. After the first 6 months, there were a few glitches that needed to be amended within the system; new policies were added to the company, and halfway through, our partner company decide to take extra security measures and added new rules to the cards" (P12, Employee) 